ANNA WINIARCZYK-RAŹNIAK

Uniwersytet Pedagogiczny w Krakowie

\title{
Dystrybucja usług medycznych w Meksyku
}

O poziomie zdrowotnym społeczeństwa decydują cztery główne grupy czynników. Należą do nich: styl życia, środowisko fizyczne i społeczne człowieka (zarówno życia, jak i pracy), czynniki genetyczne, a także służba zdrowia (Dąbrowska, Janoś-Kresło 2003). Najważniejszym zadaniem służby zdrowia jest jej skuteczne funkcjonowanie, umożliwiające prowadzenie działań na rzecz poprawy zdrowotnego poziomu społeczeństwa. Wynika ono m. in. $\mathrm{z}$ istniejącej bazy materialnej, fachowości kadry oraz struktury organizacyjnej (Załubska 1979). Szczególnie ważna jest powszechna dostępność do placówek ochrony zdrowia. Wpływa ona na wiele innych aspektów życia ludności - na poziom zdrowotny społeczeństwa, umieralność, jest także istotnym elementem składowym poziomu życia ludności.

System opieki medycznej w Meksyku od wielu lat boryka się z różnorodnymi problemami. Jednym z nich jest fakt, iż od lat 80 . znajduje się w procesie ciagłej reformy. Ponadto w porównaniu z innymi krajami regionu Ameryki Łacińskiej w PKB Meksyku obserwuje się niski udział wydatków na opiekę zdrowotną - 5,8\% (dla porównania np. w Kolumbii jest to wartość 9,3\%, w Kostaryce 7,2\%; Gómez, Ruiz 2008). Meksykańska opieka medyczna w obecnej ogólnej postaci istnieje od ok. 60 lat. Kształtowana była przez trzy kolejne reformy. Pierwsza reforma, w 1943 r., zapoczątkowała system państwowej ochrony zdrowia. Główną ideą drugiej, przeprowadzonej w latach 1979-1988, była decentralizacja państwowego systemu opieki zdrowotnej poprzez stworzenie m.in. sektorów. W trzeciej reformie, rozpoczętej w 1995 r., kontynuowany jest proces decentralizacji, tym razem na wszystkie 32 stany meksykańskie (Jaramillo Cardona 2007).

Prawo do opieki medycznej w kraju posiadało niecałe 47\% mieszkańców, najwyższy odsetek zanotowano w stanach Aguascalientes, Colima i Nuevo Leon (odpowiednio: 71\%, $70 \%$ i 69\%). Państwowa opieka medyczna zapewniana jest przez szereg instytucji, do których kierowane są środki z ubezpieczeń społecznych. Do najważniejszych zaliczane są: IMSS (Instituto Mexicano del Seguro Social), ISSSTE (Instituto de Seguridad y Servicios Sociales de Los Trabajadores del Estado), PEMEX (Petróleos Mexicanos), SEDENA (Secretaría de la Defensa Nacional), SEMAR - Secretaría de Marina-Armada de Mexico). 60\% uprawnionych do opieki medycznej osób podlegało w 2005 r. IMSS, szczególnie wysoki odsetek te osoby stanowiły w stanach położonych przy granicy z USA: Coahuila, Nuevo Leon i Chiuahua (ponad 80\%). Pod opieką ISSSTE znajdowało się 12\% uprawnionych, najwyższy odsetek zanotowano w Guerero - 32\%. PEMEX, SEDENA oraz SEMAR największe znaczenie odgrywały w stanach położonych na wybrzeżu Zatoki Meksykańskiej: Veracruz, Campeche oraz Tabasco (ponad 6,5\% uprawnionych), natomiast w skali całego kraju był to niewielki odsetek uprawnionych, bo zaledwie $2,2 \%$. 


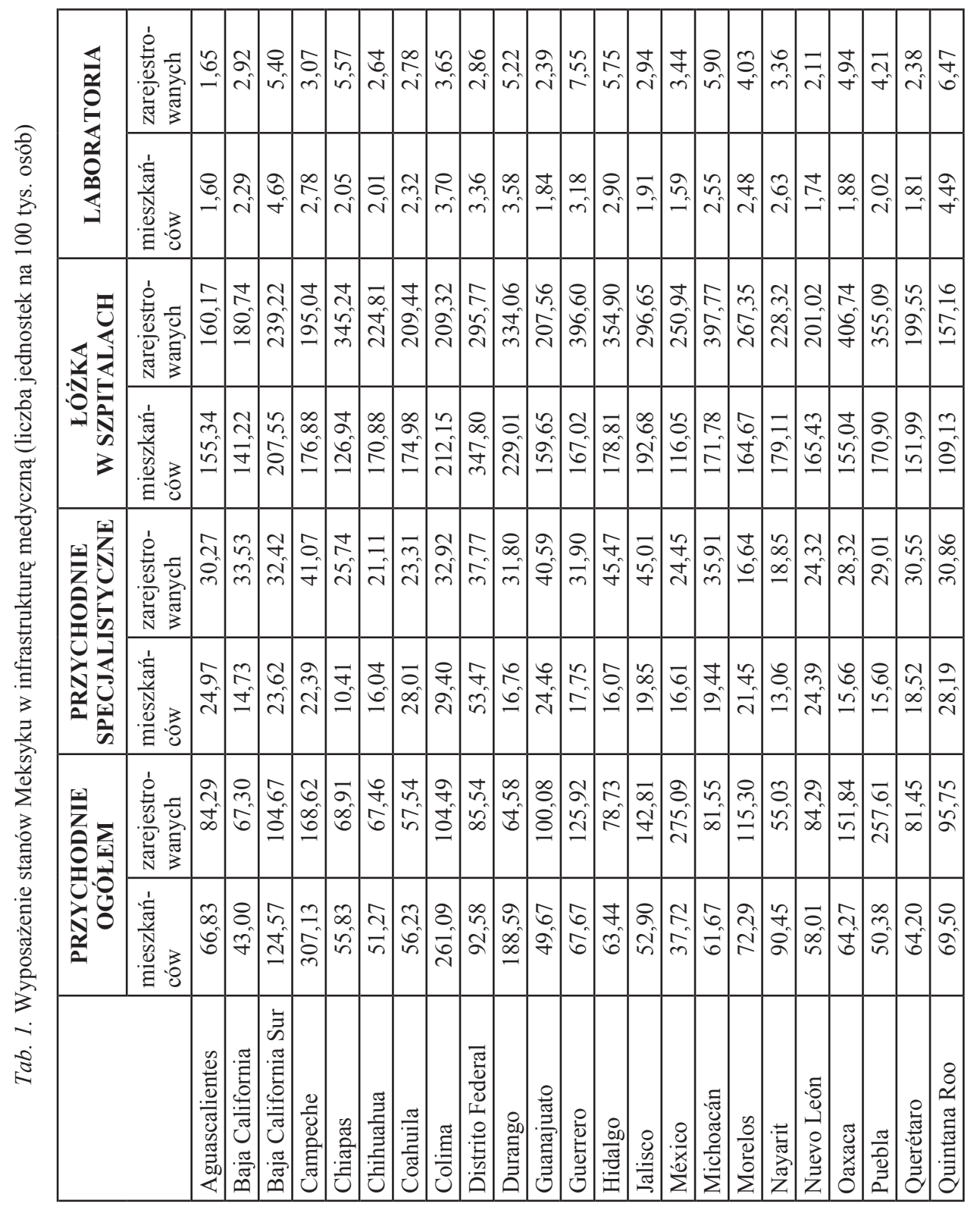




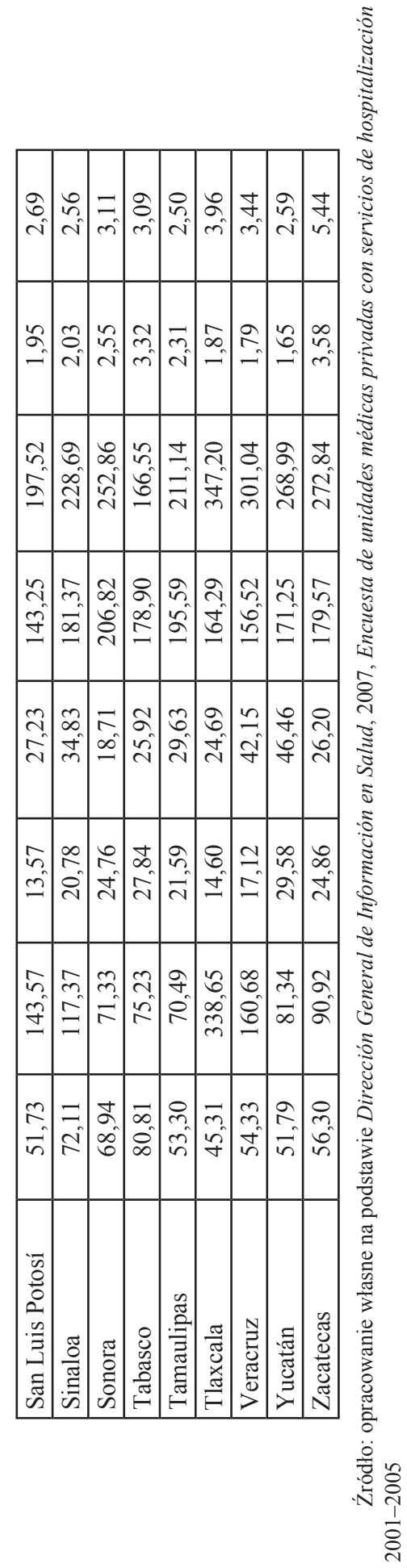


System państwowy uzupełniany jest przez placówki niepubliczne. Najwięcej jednostek prywatnej służby zdrowia (przychodni, klinik, laboratoriów itp.) w 2005 r. znajdowało się centralnej części kraju - w stanach DF, México, Hidalgo, Tlaxcala, Morelos, a najwyższą wartość wskaźnika prezentował stan Michoacán de Ocampo.

W artykule zaprezentowano przestrzenne rozmieszczenie usług medycznych na terenie Meksyku. Zbadano zatem dostępność do przychodni, szpitali (mierzoną liczbą łóżek) oraz do laboratoriów analitycznych. Dokonano także analizy zróżnicowania przestrzennego w kraju pod względem liczby personelu medycznego. W badaniu wzięto pod uwagę zarówno placówki i personel państwowy, jak i prywatny. Analizę przeprowadzono w ujęciu liczby obiektów lub personelu medycznego przypadających na 100 tys. mieszkańców (wykorzystano zatem wskaźnik nasycenia), ale także w odniesieniu do osób, które zarejestrowały się w poszczególnych stanach w różnych placówkach medycznych (nasycenie na 100 tys. zarejestrowanych osób). Zdarzało się bowiem, że w niektórych stanach, szczególnie w Distrito Federal, liczba zadeklarowanych osób (czyli rzeczywistych pacjentów) przewyższała liczbę mieszkańców. Dane wykorzystane w analizie zaczerpnięte zostały ze statystyk prowadzonych przez Instituto Nacional de Estadística y Geografía i dotyczą sytuacji, jaka miała miejsce w kraju w 2005 r. Dla placówek państwowych dostępne są nowsze dane - do 2008 r., jednak dla pełniejszego obrazu postanowiono dokonać analizy łącznie dla opieki medycznej państwowej i prywatnej, a dla tej ostatniej najnowsze dostępne statystyki kończą się na roku 2005.

W przypadku dostępności do przychodni różnego typu przypadających na 100 tys. mieszkańców najlepsza sytuacja panowała w południowo-wschodniej części kraju (stany Campeche i Tabasco) oraz w stanie Colima i w stolicy kraju (tab. 1). Inaczej sytuacja wyglądała po odniesieniu danych do liczby zadeklarowanych osób - najwyższe wartości prezentowały stany w centralnej części kraju, z wyłączeniem stolicy. Przychodnie specjalistyczne, przypadające na liczbę mieszkańców, najbardziej dostępne były w stolicy oraz na Jukatanie, natomiast w przeliczeniu na osoby zadeklarowane - również na Jukatanie (lecz nie do końca w tych samych stanach) oraz generalnie w centralnej części kraju (tab. 1). Najwięcej łóżek szpitalnych w odniesieniu do liczby mieszkańców zanotowano w stolicy kraju oraz w stanach Colima i Durango, a w odniesieniu do osób zadeklarowanych - w stanach położonych na wybrzeżu Oceanu: Oaxaca, Guerrero i Michoacán. Kolejną formą zagospodarowania infrastrukturalnego w meksykańskiej opiece medycznej były laboratoria analityczne. Również w tym przypadku wystąpiły różnice zarówno w poziomie dostępności do tych placówek, jak i pomiędzy nasyceniem na liczbę mieszkańców a na liczbę zadeklarowanych pacjentów (tab. 1). Najwyższą liczbę laboratoriów na 100 tys. osób zanotowano w stanach Baja California Sur, Quintana Roo oraz Colima, natomiast na 100 tys. pacjentów - w Guerrero, ponownie Quintana Roo oraz Michoacán de Ocampo.

Liczba personelu medycznego na różnych szczeblach w przeliczeniu na liczbę ludności jest istotnym wskaźnikiem obrazującym jakość opieki medycznej. Im większa liczba lekarzy, tym krótsze jest oczekiwanie na konsultację czy zabieg. Dostateczna liczba pielęgniarek z kolei zapewnia pełną i odpowiednią opiekę w szpitalach. Najlepsza sytuacja pod względem liczby lekarzy przypadających na 100 tys. mieszkańców panowała w Distrito Federal oraz w północnej części kraju: w stanach Nuevo Leon oraz Baja California Sur, tab. 2). Nasycenie lekarzami na 100 tys. osób zadeklarowanych najwyższe wartości prezentowało w centrum kraju: w stanach Oaxaca, Michoacan oraz Guerrero. Podobna sytuacja wystąpiła w przypadku liczby pielęgniarek - zarówno w odniesieniu do mieszkańców poszczególnych stanów, jak i rzeczywistych pacjentów (tab. 2). W przypadku dostępności do lekarzy stomatologów najlepsza sytuacja wystapiła na Półwyspie Kalifornijskim (Baja California i Baja California Sur) oraz w stanie Zacatecas, bez względu na punkt odniesienia (tab. 2). 
Tab. 2. Wyposażenie stanów Meksyku w kadrę medyczną (liczba personelu na 100 tys. osób)

\begin{tabular}{|c|c|c|c|c|c|c|}
\hline & \multicolumn{2}{|c|}{ LEKARZE } & \multicolumn{2}{|c|}{ PIELĘGNIARKI } & \multicolumn{2}{|c|}{ STOMATOLODZY } \\
\hline & $\begin{array}{c}\text { mieszkań- } \\
\text { ców }\end{array}$ & $\begin{array}{c}\text { zarejestro- } \\
\text { wanych }\end{array}$ & $\begin{array}{c}\text { mieszkań- } \\
\text { ców }\end{array}$ & $\begin{array}{c}\text { zarejestro- } \\
\text { wanych }\end{array}$ & $\begin{array}{l}\text { mieszkań- } \\
\text { ców }\end{array}$ & \begin{tabular}{|c} 
zarejestro- \\
wanych \\
\end{tabular} \\
\hline Aguascalientes & 233,05 & 240,30 & 296,32 & 305,53 & 0,38 & 0,39 \\
\hline Baja California & 203,69 & 260,70 & 199,58 & 255,43 & 6,82 & 8,73 \\
\hline $\begin{array}{l}\text { Baja California } \\
\text { Sur }\end{array}$ & 247,18 & 284,90 & 292,68 & 337,33 & 3,51 & 4,05 \\
\hline Campeche & 231,08 & 254,79 & 252,54 & 278,46 & 1,06 & 1,17 \\
\hline Chiapas & 109,00 & 296,46 & 132,46 & 360,25 & 0,37 & 1,01 \\
\hline Chihuahua & 176,03 & 231,59 & 228,23 & 300,26 & 0,37 & 0,49 \\
\hline Coahuila & 196,98 & 235,77 & 265,39 & 317,66 & 0,88 & 1,06 \\
\hline Colima & 274,12 & 270,46 & 308,80 & 304,68 & 1,06 & 1,04 \\
\hline Distrito Federal & 360,87 & 306,89 & 432,95 & 368,18 & 4,11 & 3,49 \\
\hline Durango & 196,61 & 286,79 & 235,50 & 343,53 & 0,66 & 0,97 \\
\hline Guanajuato & 178,94 & 232,64 & 184,66 & 240,08 & 2,74 & 3,56 \\
\hline Guerrero & 152,00 & 360,93 & 182,33 & 432,96 & 0,83 & 1,98 \\
\hline Hidalgo & 176,89 & 351,09 & 196,89 & 390,78 & 1,45 & 2,88 \\
\hline Jalisco & 230,52 & 354,91 & 237,58 & 365,79 & 1,27 & 1,96 \\
\hline México & 139,66 & 301,98 & 134,96 & 291,81 & 1,90 & 4,11 \\
\hline Michoacán & 189,51 & 438,82 & 187,21 & 433,51 & 1,31 & 3,04 \\
\hline Morelos & 186,12 & 302,18 & 224,01 & 363,69 & 0,74 & 1,21 \\
\hline Nayarit & 244,82 & 312,08 & 250,50 & 319,33 & 0,21 & 0,27 \\
\hline Nuevo León & 249,80 & 303,55 & 286,93 & 348,66 & 1,71 & 2,08 \\
\hline Oaxaca & 139,50 & 365,97 & 155,27 & 407,33 & 1,31 & 3,44 \\
\hline Puebla & 145,36 & 302,02 & 174,38 & 362,30 & 1,45 & 3,01 \\
\hline Querétaro & 216,06 & 283,67 & 203,49 & 267,16 & 2,88 & 3,78 \\
\hline Quintana Roo & 162,07 & 233,39 & 162,07 & 233,39 & 3,17 & 4,57 \\
\hline San Luis Potosí & 172,42 & 237,73 & 195,03 & 268,91 & 1,24 & 1,72 \\
\hline Sinaloa & 202,73 & 255,61 & 256,93 & 323,96 & 0,92 & 1,16 \\
\hline Sonora & 260,39 & 318,37 & 271,37 & 331,79 & 0,92 & 1,12 \\
\hline Tabasco & 223,22 & 207,82 & 230,00 & 214,13 & 0,70 & 0,65 \\
\hline Tamaulipas & 212,32 & 229,20 & 260,69 & 281,43 & 1,72 & 1,86 \\
\hline Tlaxcala & 201,55 & 425,94 & 192,28 & 406,36 & 2,06 & 4,35 \\
\hline Veracruz & 165,44 & 318,19 & 182,03 & 350,11 & 0,82 & 1,57 \\
\hline Yucatán & 201,93 & 317,18 & 247,29 & 388,42 & 2,53 & 3,97 \\
\hline Zacatecas & 182,50 & 277,28 & 192,81 & 292,94 & 4,53 & 6,89 \\
\hline
\end{tabular}

Źródło: opracowanie własne na podstawie Dirección General de Información en Salud, 2007, Encuesta de unidades médicas privadas con servicios de hospitalización, 2001-2005 
Jak wcześniej wspomniano, dane dotyczące infrastruktury oraz personelu medycznego wykorzystano do stworzenia wskaźników nasycenia na liczbę mieszkańców oraz pacjentów zadeklarowanych w poszczególnych stanach. W większości przypadków wskaźniki te różnią się znacznie między sobą. Ryc. 1 prezentuje, o ile procent wyższe są wartości, jeśli weźmie się pod uwagę właśnie liczbę osób rzeczywiście korzystających z usług medycznych w poszczególnych stanach. Najlepsza sytuacja pod tym względem wystąpiła w stanach w centralnej części kraju, w których rzeczywista dostępność była najlepsza: Oaxaca, Guerrero oraz w Chiapas. Z powodu znacznie wyższej liczby pacjentów niż liczby ludności w trzech stanach zaobserwowano gorszą sytuację pod względem dostępności do usług medycznych, niż wskazywałyby na to oficjalne wskaźniki - w stolicy, stanie Tabasco oraz w stanie Colima.

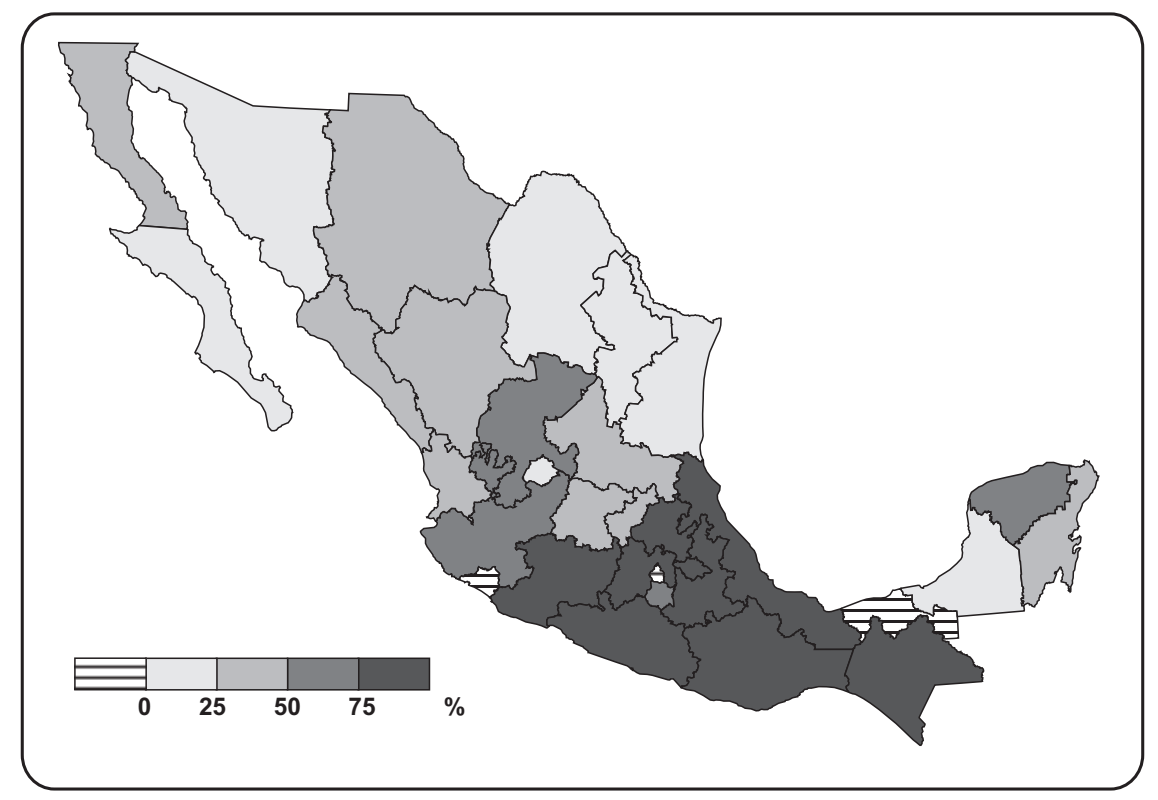

Ryc. 1. Różnice we wskaźnikach obliczonych na 100 tys. zarejestrowanych osób w stosunku do wskaźników obliczonych na 100 tys. mieszkańców

Źródło: opracowanie własne

Na podstawie danych liczbowych, dotyczących wybranych wskaźników państwowej opieki medycznej, dostępnych dla lat 1995 i 2005, stworzono syntetyczną miarę. Dobraną grupę wskaźników przeanalizowano, eliminując te z nich, które były nadmiernie ze sobą skorelowane, co pozwoliło na uniknięcie współliniowości cech. Ostatecznie do dalszego procesu badawczego zakwalifikowano cztery cechy: liczba łóżek w szpitalach na 100 tys. mieszkańców, liczba przychodni na 100 tys. mieszkańców, liczba stomatologów na 100 tys. mieszkańców oraz stopień zapełnienia szpitali (w \%). W przypadku destymulanty obliczono odwrotność tego miernika, co pozwoliło na stworzenie grupy cech o jednakowym skierowaniu. Następnie otrzymane wartości wskaźnika syntetycznego dla obu badanych przekrojów czasowych podzielono na trzy grupy. Dzięki temu można było porównać wszystkie stany pod względem ogólnej dostępności do usług medycznych w poszczególnych latach oraz zbadać, czy sytuacja się zmieniła pod tym względem w ciągu 11 lat (tab.. 2). 
Tab. 2. Syntetyczny wskaźnik dostępności do usług medycznych w latach 1995-2005

\begin{tabular}{|c|c|c|}
\hline & $\begin{array}{c}\text { WSKAZNIK } \\
\text { SYNTETYCZNY } \\
1995 \\
\end{array}$ & $\begin{array}{c}\text { WSKAZNIK } \\
\text { SYNTETYCZNY } \\
2005 \\
\end{array}$ \\
\hline Asuascialientes & 0,02 & 0,03 \\
\hline Baja California & $-0,35$ & $-0,59$ \\
\hline BajaCalifornia Sur & 1,56 & 0,93 \\
\hline Campeche & $\mathbf{0 , 0 8}$ & 0,73 \\
\hline Chiapas & $-0,37$ & $-0,21$ \\
\hline Chihuahua & $-0,44$ & $-0,48$ \\
\hline Coahuila de Zar agoza & 0,31 & $-0,02$ \\
\hline Colima & 0,59 & 0,90 \\
\hline Distrito Federal & 1,71 & 1,10 \\
\hline Durango & $-0,01$ & 0,40 \\
\hline Guanajuato & $-0,60$ & $-0,87$ \\
\hline Guertero & $-0,24$ & 0,19 \\
\hline Hidalgo & $-0,70$ & $-0,18$ \\
\hline Jalisco & 0,44 & $-0,04$ \\
\hline Méxioo & $-0,30$ & $-0,56$ \\
\hline Michoacifin de Ocampo & $-0,44$ & $-0,39$ \\
\hline Morelos & $-0,31$ & 0,03 \\
\hline Nayarit & 0,23 & 0,23 \\
\hline Nuevo Le'n & 0,00 & $-0,16$ \\
\hline Oaxaca & $-0,29$ & $-0,27$ \\
\hline Puebla & 0,09 & $-0,02$ \\
\hline Quer étaro Arteasga & $-0,27$ & $-0,49$ \\
\hline Quintana Roo & 0,05 & $-0,50$ \\
\hline San Luis Potod & $-0,41$ & $-0,39$ \\
\hline Sinaloa & $-0,32$ & 0,19 \\
\hline Sonota & 0,27 & 0,33 \\
\hline Tabassoo & 0,43 & 0,76 \\
\hline Tamaulipas & 0,10 & $-0,01$ \\
\hline Tlaxcala & $-0,15$ & $-0,23$ \\
\hline Veractuz de I gnacio de la Llave & $-0,32$ & 0,00 \\
\hline Yucatín & 0,05 & $-0,36$ \\
\hline Zaciatecias & $-0,54$ & $-0,32$ \\
\hline
\end{tabular}




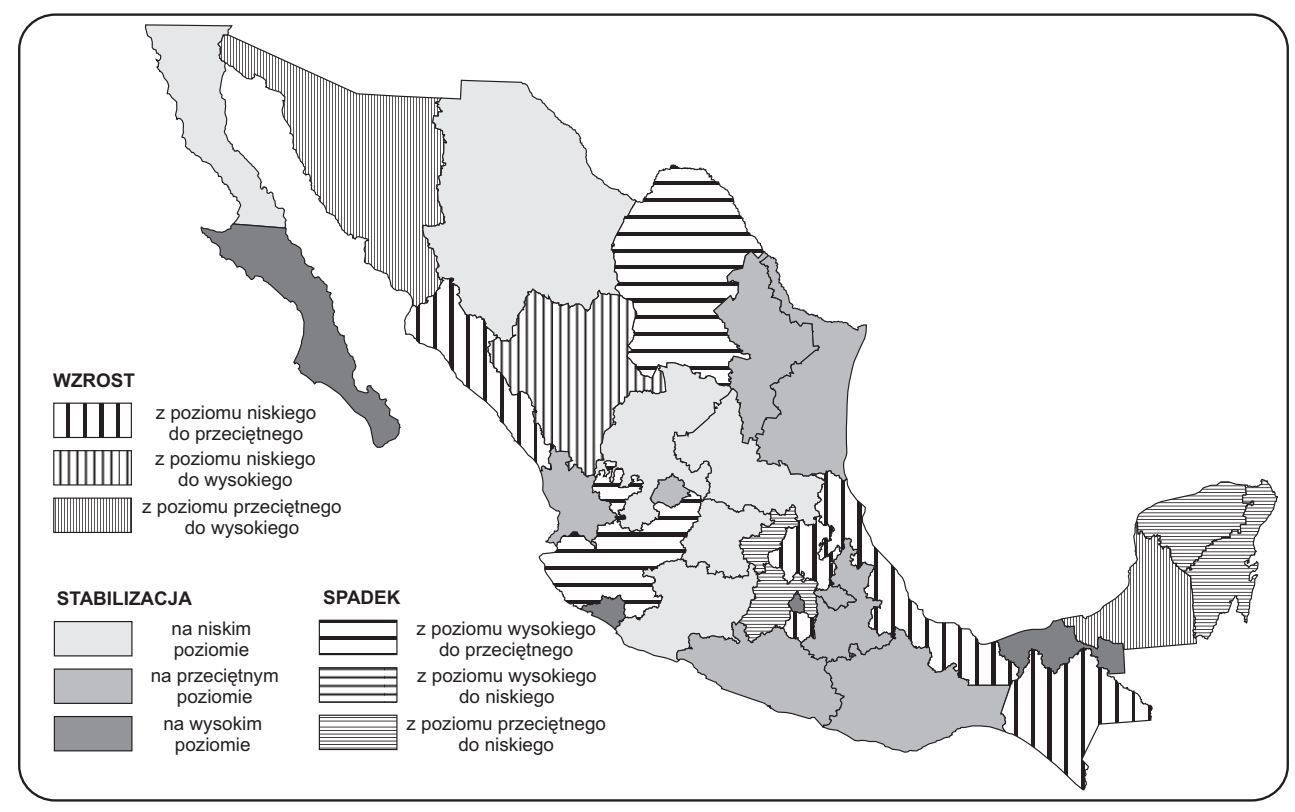

Ryc. 2. Syntetyczny wskaźnik dostępności do usług medycznych dynamika zmian w latach 1995-2005

Źródło: opracowanie własne na podstawie Anuario de estadisticas por entidad federativa 2005, 2009

W roku 1995 zaobserwowano występowanie 11 stanów o niskiej dostępności do usług medycznych, 15 na poziomie przeciętnym i 6 na poziomie wysokim. W roku 2005 zmniejszyła się grupa stanów o niskiej dostępności (o jeden stan), a zwiększyła się o jedną jednostkę administracyjną grupa stanów najlepiej wyposażonych w usługi medyczne. Układ tych grup charakteryzował się nieco odmienną konfiguracją w obu badanych przekrojach czasowych.

Na podstawie zmian obliczonych wskaźników syntetycznych poszczególne stany zakwalifikowano do jednego z dziewięciu typów. Były to: stabilizacja na poziomie niskim, stabilizacja na poziomie przeciętnym i stabilizacja na poziomie wysokim, trzy typy wzrostowe (z niskiego do przeciętnego, z niskiego do wysokiego i z przeciętnego do wysokiego) oraz trzy typy stanów charakteryzujących się spadkiem (z poziomu wysokiego do przeciętnego, z wysokiego do niskiego oraz z przeciętnego do niskiego, ryc. 2). Okazuje się, iż w okresie 1995-2005 ponad połowa - bo 18 na wszystkie 32 stany - charakteryzowała się stabilizacją na poziomie prezentowanym w wyjściowym momencie dla badania (dotyczyło to głównie stanów położonych w centrum kraju) i była to głównie stabilizacja na poziomie przeciętnym (8 stanów). W typie wzrostowym znalazło się 8 stanów (25\% badanej grupy) - zaobserwowano przede wszystkim wzrost z poziomu niskiego do przeciętnego. Przy czym nie widać w tym przypadku żadnego konkretnego układu przestrzennego tych jednostek - były to stany położone na północy kraju, w centrum, a także na południu. Najmniejsza grupa jednostek administracyjnych charakteryzowała się spadkiem poziomu dostępności do usług medycznych - było to 6 stanów, z czego większość obniżyła poziom z przeciętnego do niskiego (m.in. stany na Półwyspie Jukatán oraz stan México położony w Obszarze Metropolitalnym Valle de México). 
Podsumowując, opieka medyczna w Meksyku po kolejnych reformach zdywersyfikowana jest na różne instytucje. W kraju zaobserwować można zróżnicowanie pod względem dostępności do usług medycznych, zarówno w wymiarze wyposażenia infrastrukturalnego, jak i personelu medycznego na różnych szczeblach. Dodatkowo sytuację komplikuje fakt, iż w niektórych stanach liczba rzeczywiście zadeklarowanych pacjentów znacznie odbiega od ogólnej liczby mieszkańców, szczególnie w stolicy kraju. Badanie wykazało ponadto, iż pomimo reform, sytuacja pod względem dostępności do usług medycznych nie poprawiła się w znaczącym stopniu, a w części stanów zaobserwowano pogorszenie się sytuacji.

\section{Literatura}

Anuario de estadísticas por entidad federativa, 2005, Instituto Nacional de Estadística y Geografía, Aguascalientes.

Anuario de estadísticas por entidad federativa, 2009, Instituto Nacional de Estadística y Geografía, Aguascalientes.

Dirección General de Información en Salud, Secretaría de Salud, México 2007.

Dąbrowska A., Janoś-Kresło M., 2003, Znaczenie ustug społecznych w ksztattowaniu jakości życia mieszkańców, [w:] Jakość życia w regionie, red. J. Karwowski, Uniwersytet Szczeciński, Szczecin, s. 233-240.

Encuesta de unidades médicas privadas con servicios de hospitalización, 2001-2005, Instituto Nacional de Estadística y Geografía, Aguascalientes.

Gómez M.A., Ruiz T., 2008, México: servicios públicos médicos de atención a población abierta: El caso del Hospital General Manuel Gea González, The Center for Migration and Development, Working Paper Series, Princeton University, 08-051.

Jaramillo Cardona M. C., 2007, La descentralización de la salud en México: avances y retrocesos, Rev. Gerenc. Polit. Salud, Bogotá, 6 (13), 85-111.

López-Arellano O., Blanco-Gil J., 2001, La polarización de la política de salud en México, Cad. Saúde Pública, Rio de Janeiro, 17(1), 43-54.

Załubska I., 1979 - Stużba zdrowia, [w:] Miejskie województwo krakowskie - elementy struktury geograficzno-ekonomicznej, Folia Geographica, Series Geographica-Oeconomica, Vol. XII, Wrocław-Warszawa-Kraków-Gdańsk, s. 157-166

\section{Distribution of medical services in Mexico}

The fundamental purpose of healthcare industry is to effectively provide medical services that improve the quality of health in a given society. The most important issue is the issue of access to medical facilities. The paper presents the spatial distribution of medical services across Mexico. This includes access to hospitals, clinics, and analytical laboratories, as well as the number and profile of medical personnel, as measured by the number of physicians, nurses, and dentists. Available data was used to construct a comprehensive index that was used to determine whether medical care in Mexico had become more or less accessible from 1995 to 2005.

dr Anna Winiarczyk-Raźniak

Uniwersytet Pedagogiczny im. Komisji Edukacji Narodowej w Krakowie

Instytut Geografii

Zakład Geografii Społeczno-Ekonomicznej

e-mail: arazniak@poczta.fm 